\title{
To reduce the Turn Around Time (TAT) of trucks and improve in-plant logistics
}

\author{
Kautuk Timane ${ }^{1}$, Puneet Gusain ${ }^{2}$, Dr. Prashant Barge ${ }^{3}$ \\ ${ }^{1}$ PG Student, Symbiosis Institute of Operations Management, Nashik, Maharashtra, India. \\ ${ }^{2}$ Associate Consultant at Infosys Limited, Pune, Maharashtra, India. \\ ${ }^{3}$ Assistant Professor at Symbiosis Institute of Operations Management, Nashik, Maharashtra, India.
}

\begin{abstract}
This paper talks about the reduction of in plant operations time and reduction of turn-around time of the trucks in any FMCG Company. The plant has almost 300 vehicles for loading and unloading. The current systems and process for receiving and dispatching of goods is poised with several challenges. This process with the inspection of material at the entry of a truck to the billing procedures in an effective manner is a challenge due to various constraints. The load, which needs to be dispatched in a day, requires a very less turnaround time of trucks but the actual time, when analysed, was significantly higher than what was required. Higher turnaround time was causing ineffective operations in terms of placing the vehicles in the plant by the transporters. Subsequently, there was a considerable deviation between the planned orders to be dispatched and actual dispatch of goods. The complete process was studied for identifying the loopholes and time motion study was conducted to analyse the current issues, which was leading to more VIVO time of vehicles. The whole process was analysed and thus major factors, which were causing the delay of the vehicles were identified. A survey was conducted to pen down the issues causing the problems in managing the in-plant logistics of the company. Results were analysed and was found that deployment of more manpower and optimizing the entire process would help only marginally towards achieving the goal. Hence, automating the redundant and timeconsuming activities would help in achieving a considerable amount of reduction in the turn-around time of trucks. This will indirectly increase the dispatch quantities of the company. In addition, there is a requirement to redefine work, which would primarily mean altering the original process. Thus, various issues in the existing processes were identified and reduction in turnaround time was observed with the implementation of the new process and tools used to reduce the redundant processes.
\end{abstract}

\section{KEYWORDS:}

TAT, SOP, Optimisation, Automation, Bottlenecks, RCA

Article Received: 10 August 2020, Revised: 25 October 2020, Accepted: 18 November 2020

\section{Introduction}

The FMCG sector, since its inception is growing at a faster rate than any other sector. The changes being introduced are immense and the competition is forever increasing. The companies are focusing on reducing the old and time-consuming processes to make the firm more profitable by bringing down lead-time. Garrido Azevedo, S. and Carvalho, H. (2012) This enhances the responsiveness of the company towards the demand and maintains right balance in the operation. One of the fronts where the FMCG industry is facing challenges is the market sentiments. Hence forecasting the demand to supply its products while managing the uncertainty in the market is highly challenging. (Vayvay, Özalp \& Dogan, Ozlem \& Özel, Semih, 2013). Managing these problems may become cumbersome and may affect the responsiveness of demand, especially if the planning and operations is not streamlined. Thus it depends how effective and flexible is the operations of entire supply chain of the company, which will deliver the goods to the market.

One of the major challenges, that a FMCG company experiences, is its distribution. As huge loads are distributed continuously, the planning and management plays a major role in distribution network of a company. The various nodes of distribution network could be affected by even a small bottleneck in the production unit and warehouse of the manufacturing plant. This jeopardises the distribution which results in reduced sales and profit for the company. (Gilmour, Brad \& Gale, Fred,2002)

The study reflects one aspect of streamlining and achieving greater productivity for the entire distribution network of a FMCG company. As the number of vehicles entering and leaving the company, are more for the dispatch and receiving of goods, it is essential to streamline the entire 
operations in plant, which will lead to better working conditions, and increased throughput of the plant. Hence, managing the plant operations to help company achieve more sales and increased throughput capacity will increase the sales and responsiveness of demand. Streamlining the processes and use of new measures to reduce paper work and manual intervention will help in achieving a balance.

The in-plant operations was studied and bottlenecks and time consuming activities were identified. The use of QR code, improved process flow, dedicated parking slots, streamlined process for invoicing and documentation were used and implemented which helped the company reduce vehicle in vehicle out time.

\section{LITERATURE REVIEW}

The focus of my research is to improve the inplant logistics operation and reduction of TAT for trucks that involves the study and analysis of the system. Warehouse is a nervous system and most important element of the logistics system. The manner in which it is setup has an impact on all other parts and elements in the company. There are several basic principles of logistics:

Maximum possible mechanization and automation of operations;

Optimal utilization of space and area of storage facilities

Organization by "continuous-flow" of stocks;

Safety and security not by creating bottlenecks for the dispatch flow out from the plant

Truck turnaround time or the amount of time required or taken by the vehicle to enter the plant, finish all activities in the plant \& exit the plant makes a significant worry to all plants and company. It result in traffic \& consequently coalescence of trucks at unloading, causing time delays. Furthermore increasing the no. of trucks in the factory additionally increases effectiveness of the plant. In FMCG companies, where the goods and raw material required is high and furthermore the parts are huge in quantities and variety, and with this the task to distribute the finished goods to the customers require planning and thus, TAT turns into a main consideration to assure higher efficiency of the entire plant. (Kushal Parwani and R Jagadeesh, 2012)

It is apparent to consider that warehouses to think not as area for the stockpiling of the goods, they are important part of the supply chain which facilitates the transportation of goods and storage of goods. There are various activities which a warehouse facilitates should as inward, outward, storage. Warehouses aids in the conversion of goods transportation by altering the parameters of accepted and issued consignments in shape, size, composition, inspection of physical characteristics of the inward materials, and time required (Khanzode, Vivek \& Shah, Bhavin, 2017). The details of the warehouse, gives the presence of inventory considered as a vital factor in confirming a certain level of service to the customer. In turn, customers believe causes the creation of reserves to ensure the link of the production process, the search of streamlined flow and provide fast shipment at the unanticipated demand of various goods. Optimised in plant logistics leads to minimization of inventory cost by streamlined flow of goods, so warehouses provide facilities and special strategies for the storage of goods, to satisfy needs of logistics and distribution channel. (Langevin \& Riopel, 2005).

Distribution Center Management article (Kenneth Ruebrdanz, 2011) also gives the golden rules for the optimization of the warehouse operations. These mainly discuss the storage techniques, picking efficiency, travel time, order processing.

Warehouse and in-plant operation management (Michael Hompel, 2007) also helped a lot in the order picking and warehouse organisation. It helped in the applying various storage techniques like $\mathrm{ABC}$ analysis, sorting systems, sequencing of the orders etc. The authors have taken the term warehouse management and plant operations to describe the processes and technologies. Nowadays, the majority of transportation and management system undoubtedly are computer-controlled with add on functions like the controlling of transport and order processing activities to fulfil demand. Inplant logistics management generally means the control and optimization of intricate warehouse and distribution systems. In addition to the elementary functionality of an logistics management like the management of quantities and storage locations, the control and planning of transport means according to this principle warehouse management also comprises methods and means to control the system status and to choose an operating and optimization strategy. 
(Rodrigues, Vasco \& Potter, Andrew \& Naim, Mohamed, 2010) expressed that principle factors affecting coordination activities are postponements of conveyance, flexibly limitations, absence of coordination, variable interest, and helpless data. The outcome of these varieties is the decrease of productivity in overseeing transport activities. (Ying, Tookey, and Roberti (2015) led an examination on subcontractors and their capacity to convey items. In the examination, it was discovered that one of the principle challenges in giving great coordination of administrations was an absence of arranging of material conveyances and emptying among the subcontractors and their site workforce. The absence of interchanges between them can be ascribed to nonexistence of formal systems for buying. The staffs of the subcontractors need to manage different strategies when requesting materials. Aside from that, it was additionally discovered that providers only occasionally refreshed their capacity to convey requested materials on an ideal opportunity to the site staffs. This enormously influenced the productivity of the coordination exercises inside the organizations. A similar circumstance could likewise be found in the Nordic gracefully chain (Ülgen and Forslund, 2015). Just little proof of joint efforts can be found with respect to their capacity to focus on any conveyances. Moreover, need coordinated IT uphold has added to the little close to home correspondence occurring between the flexibly chain individuals.

\section{METHODOLOGY}

Steps followed for studying the system and thus re Mapping the entire process flow inside the plant Collection of real time data to explain the situation, so this data which is collected can be used from comparative study

Determination of root cause and bottlenecks in the system

Identify the solutions to optimise the entire inplant logistics operations

The research is completely based on the collection of the factual quantitative data followed by a quantitative research methodology. Quantitative research explains, draws interferences, and resolves problems with the help numbers. Emphasis is placed on the collection of numerical data, the summary of those data and the drawing of inferences from the data (John Dudovskiy,
2019). It is a fundamental research study involving on field data, which gives the idea of how a plant is operated. The data collected is analysed to identify the bottlenecks in the current TAT process of dispatching vehicles from the warehouse and to find out issues in the order to cash cycle process.

The implementation of a strategy based on measurement focuses on process improvement and variation reduction which is the Fundamental objective of the Six Sigma methodology. This can be achieved by systematically using Six Sigma methodology which is DMAIC (DefineMeasureAnalyze-improve-Control). (Suhas N. Karajgar, Dr. D. N. Raut, 2018)

The research follows an exploratory form of design involving investigation areas, which are causing the delay in the dispatch of the vehicle from the plant. Exploratory studies only aim to explore the research area and they do not attempt to offer final and conclusive answers to research questions (Stebbins, Robert, 2001). Research does not follow a rigid structure and is multidisciplinary. As well as the primary data that was collected during the tenure of study for the order to invoice. The convenience sampling has been used while collecting the data. The complete study of all the TAT activities that contribute to the effective dispatch of vehicles from both the warehouses are analysed. Different methods were followed for data collection of the different processes. All these methods were modelled in Microsoft Excel for e.g. the time motion study, surveys from drivers asking the questions related to the movement of vehicle for the entire order processing.

Descriptive statistical analysis of the data has been carried out in Microsoft Excel. Descriptive statistical analysis of data helps describe, show or summarize data in a meaningful way such that, for example throughput can be calculated from the data.

Descriptive statistical analysis of data helps describe, show or summarize data in a meaningful way such that, for example, patterns might emerge from the data. Descriptive statistics however, does not help us to make inferences or conclusions other than the data which have been analysed or even reaching to the conclusions regarding any hypotheses which are considered. They are simply a way to describe our data (Thompson, Cheryl, 2009). 
It was essential to comprehend nature where the work was created just as the relating objectives and limitations. Besides, it was imperative to gather writing about the current issue to locate the prescribed procedures, techniques and instruments applied in a comparative setting.

All the plants producing different types of goods are located in same facility spread over a huge area. The complete demand was catered from only two warehouses in one plant location. Thus, this required a huge network of vehicles and effective warehouse operations. These warehouses were dispatching the goods to entire central and southern part of India. The logistics operations involved a large number of transporters and agencies.

The in-plant operation is analysed and thus we get the below process which is generally being followed:

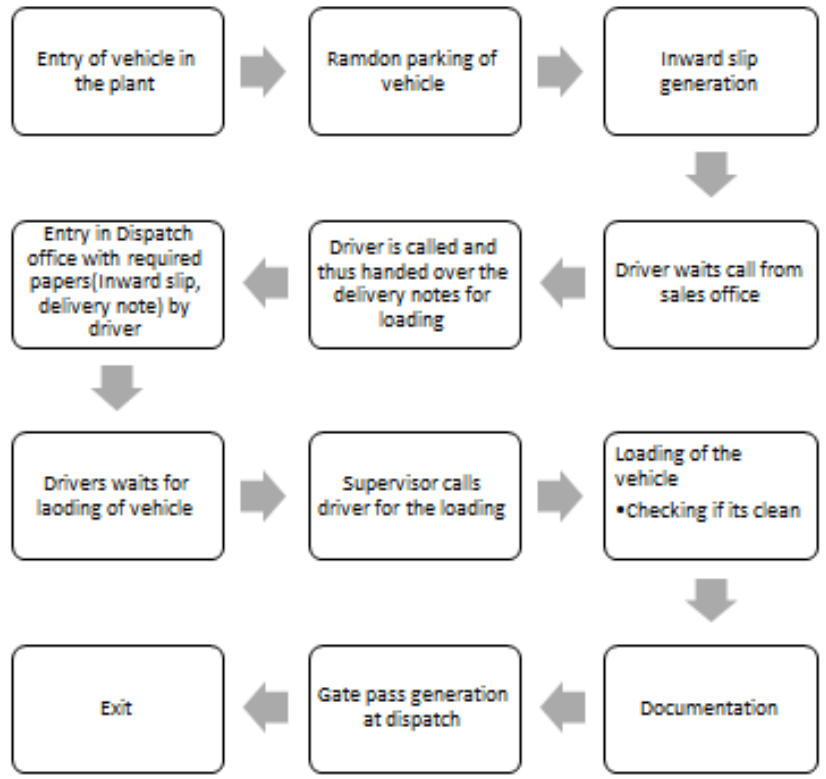

Figure 1: Process flow of the in-plant operations

Source: By Author

Survey was conducted for the truck drivers after analysing the entire process. Below is the results of the data collected from the various drivers. Sample of 95 truck drivers was taken in-plant across the period of 30 days. So this gives an idea for the entire operations of peak and normal load over the period. The sample size tells the

\begin{tabular}{|l|l|l|l|l|l|l|l|l|l|}
\hline $\begin{array}{l}\text { Area } \rightarrow \text { / } \\
\text { Priority } \downarrow\end{array}$ & $\begin{array}{l}\text { Entry } \\
\text { gate }\end{array}$ & Inspection & $\begin{array}{l}\text { Inward slip } \\
\text { generation }\end{array}$ & $\begin{array}{l}\text { Parking } \\
\text { Area }\end{array}$ & $\begin{array}{l}\text { Loading } \\
\text { area }\end{array}$ & $\begin{array}{l}\text { DN } \\
\text { generation }\end{array}$ & Invoicing & $\begin{array}{l}\text { Gate } \\
\text { generation }\end{array}$ & $\begin{array}{l}\text { Clumsy } \\
\text { process }\end{array}$ \\
\hline 1 & 2 & 0 & 35 & 5 & 7 & 28 & 31 & 22 & 38 \\
\hline 2 & 1 & 5 & 31 & 7 & 12 & 22 & 28 & 17 & 28 \\
\hline 3 & 3 & 8 & 11 & 15 & 11 & 21 & 19 & 22 & 19 \\
\hline 4 & 11 & 13 & 10 & 31 & 7 & 10 & 10 & 15 \\
\hline 5 & 20 & 29 & 3 & 20 & 33 & 5 & 2 & 10 & 0 \\
\hline 6 & 58 & 40 & 5 & 17 & 25 & 9 & 5 & 9 \\
\hline
\end{tabular}

Table 1: Priority frequency rating of delay by truck drivers (Sample size-95)

The Truck Drivers:

The following instances where the drivers were supposed to interact with the employees of the plant, which required generation of various documents.

- Reporting to Plant's main gate

- Verification of all the driver and license details of the vehicle with proper paper

- Presentation of trucks for security verification and an entry recording of the truck

- Inward slip generation at the entry
- Communication with the sales office regarding the loading of goods

- Entry in sales office for handing over the papers and picklist

- Entry in dispatch office for getting seal for trucks

- Communication by loading supervisor to truck driver via mic for loading of goods

- Driver checks the loaded quantities in the truck and cross verified by the driver

- Entry of the driver in sales office for the bill and LR receipt generation 
- Entry of the driver in the dispatch office for gate pass generation

Analysis

Observation 1: Loading operation for outbound dispatch is not the main component for TAT. The other components acts as a hurdle for the performance of entire system.

The loading operations take 30 minutes on average for 300 cartons. The time required for the loading and the waiting time is shown which may contribute to the value adding and not value adding time.

\begin{tabular}{|c|c|c|c|}
\hline \multicolumn{4}{|c|}{32 Feet Vehicle } \\
\hline & $\begin{array}{l}\text { Loading } \\
\text { time(min) }\end{array}$ & $\begin{array}{l}\text { Cumulative waiting } \\
\text { time (mins) }\end{array}$ & $\begin{array}{lll}\text { Cumulative } & \text { time } & \text { for } \\
\begin{array}{l}\text { Documentation, } \\
\text { generation (mins) }\end{array} & \text { invoicing, } & \text { LR } \\
\end{array}$ \\
\hline Average & 35 & 150 & 60 \\
\hline Max & 50 & 320 & 80 \\
\hline \multicolumn{4}{|c|}{20 feet Vehicle } \\
\hline Average & 25 & 160 & 50 \\
\hline Max & 45 & 350 & 70 \\
\hline
\end{tabular}

Table 2: Time required for different activities

Observation 2: The bottleneck activity is manual inward slip generation and documentation. The time consumed in the other activities like waiting for generation of various documents that could be done easily and quickly with modern technologies. This delay is visible in the Table 2 where we can see that the loading time is very less as compared to the other activities that are nonvalue adding activities.
Observation 3: A gap in various types of activities, which are conducted and the time consumed for such activities is observed. There were different offices and departments where the driver has to move in the plant. The entire operation from loading till the gate pass generation was tedious so this was the major contributor for the turnaround time increase for various trucks.

\begin{tabular}{|l|l|}
\hline Agency & Work \\
\hline Transporter & Arranging vehicles, LR generation \\
\hline Security & $\begin{array}{l}\text { Checking each and every vehicles for security } \\
\text { purpose, driving licences of the drivers, gate } \\
\text { pass, invoices, supervision of the parked } \\
\text { vehicles }\end{array}$ \\
\hline Despatch section & $\begin{array}{l}\text { Sequencing of vehicles, providing necessary } \\
\text { documents to the drivers, control on the loading } \\
\text { activities }\end{array}$ \\
\hline $\begin{array}{l}\text { Weighbridge } \\
\text { operations }\end{array}$ & $\begin{array}{l}\text { Inward slip generation, cross verification of } \\
\text { vehicles against the details provided }\end{array}$ \\
\hline Sales section & $\begin{array}{l}\text { Generation of Delivery notes, Invoicing of } \\
\text { loaded quantities, LR generation, Adjustments } \\
\text { for load in vehicles, DN printing }\end{array}$ \\
\hline $\begin{array}{l}\text { Loading } \\
\text { operators }\end{array}$ & $\begin{array}{l}\text { Loading of vehicles, Material retrieval, } \\
\text { inspections of loaded goods, cross verification } \\
\text { of loaded goods }\end{array}$ \\
\hline
\end{tabular}

Table 3: Agencies and their work

Observation 4: Uneven and fragmented distribution of work; there is less focus on the responsive to the demand; several NVA activities; too many documents; tedious process. The different documents and the involved agencies are shown in the table 4.

The truck driver needs to stop at 6 locations before completing the entire process of dispatch 
- He has to interact with six different departments before completing his work

- 6 documents for the processing of an order, were required to be generated before a truck exit the system. Each document required the cooperation of different departments in and outside the plants

\begin{tabular}{|c|c|c|c|c|}
\hline & Document & Location & Agencies involved & Comments \\
\hline 1 & Inward slip & Entry gate & $\begin{array}{l}\text { Driver, } \\
\text { Bridge }\end{array}$ & Adds to delay \\
\hline 2 & DN Generation & Sales office & $\begin{array}{l}\text { Company workers, } \\
\text { Driver }\end{array}$ & $\begin{array}{l}\text { Adds to delay due to } \\
\text { manual entry of vehicle in } \\
\text { the system }\end{array}$ \\
\hline 3 & $\begin{array}{l}\text { Delivery receipt } \\
\text { at dispatch office }\end{array}$ & Dispatch office & $\begin{array}{l}\text { Dispatch workers, } \\
\text { drivers }\end{array}$ & $\begin{array}{l}\text { Queue due to manual } \\
\text { entry in registers }\end{array}$ \\
\hline 4 & $\begin{array}{l}\text { Invoice } \\
\text { generation }\end{array}$ & Sales office & $\begin{array}{l}\text { Sales office } \\
\text { workers, driver }\end{array}$ & $\begin{array}{ll}\text { Addition } & \text { of extra } \\
\text { quantities, } & \text { adjustments } \\
\text { takes time } & \\
\end{array}$ \\
\hline 5 & LR generation & Sales office & $\begin{array}{l}\text { Sales office } \\
\text { workers, } \\
\text { transporter, driver }\end{array}$ & $\begin{array}{l}\text { Adds delay due to } \\
\text { separate LR copy for all } \\
\text { the transporters and its } \\
\text { availability }\end{array}$ \\
\hline 6 & Gate Pass & Dispatch office & $\begin{array}{l}\text { Dispatch workers, } \\
\text { driver }\end{array}$ & $\begin{array}{l}\text { Delay and mistake due to } \\
\text { manual generation of } \\
\text { Gate pass }\end{array}$ \\
\hline
\end{tabular}

Table 4: Documents to be generated from various departments
Observation 5: Company not able to stick to or complete the dispatch plan provided to them due to more TAT and inefficient in plant logistics. Poor performance arising out of complicated processes. This in turn leads to blocking of goods in the plant

There is variation in the planned \& actual dispatch so goods. The deviation ranges between $20 \%$ and $10 \%$.

Observation 6: The entire processes are poorly designed and managed. The redundant and unnecessary movement of people in the plant is cumbersome.

Variation in the dispatch rate, prolonged working hours, long delays in TAT

The process requires an immediate attention with a structured SOP. The standard plants operating in the same industry requires a truck to stop at 2-3 locations inside the plant.

Duplication in tasks, gap in the sharing information and processes leading to poor coordination of truck drivers and the employees of the plant leading to create noise inside the plant.
- TAT is not the focus for the various departments. Every department was working in silos to complete the allotted task to them.
Sales Volumes are expected to increase drastically. The drivers and transporters who arranges the vehicle are unwilling to visit the warehouse in view of huge TAT, company and transporter are focus on lower cost of distribution.

Observation 7: Huge scope of automation.

The various processes are managed with manual data entry. The waiting time for each of the activities increases and the errors occurring due to manual entry is high. The use of integrated system in the entire plant is need of an hour. Computer controlled robust IT system to store and retrieve the data transactional data for preparing various documents with technological advancement will provide immense help to the entire system.

Issues causing increased turnaround time are listed:

More time in manual inward slip generation Unorganised parking of vehicle leading to traffic jam in the plant

Manual entry of the vehicle details in dispatch office 
Un structured process flow in the loading operations from both the warehouses

Working of dispatch and sales teams in silos

No SOP for truck drivers and loading supervisors

In addition, all the data collected was analysed, after the analysis of the data to find out the variables impacting the TAT more were found out.

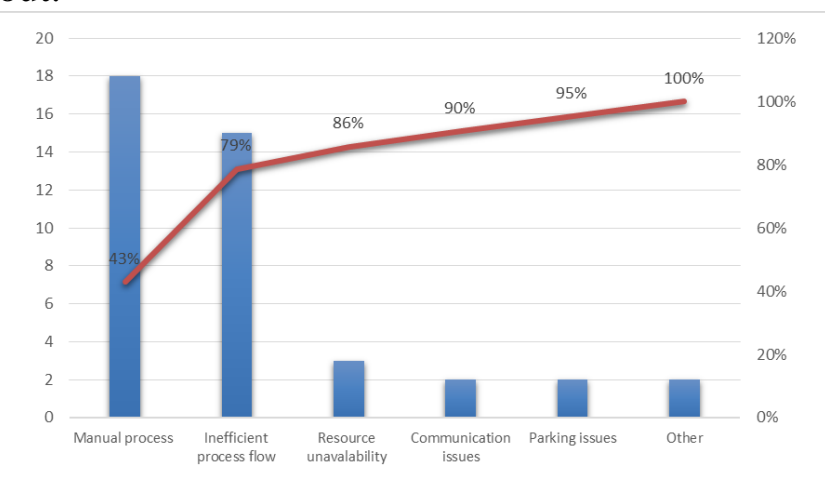

Figure 2: Pareto Analysis of issues for more TAT

\section{Approaches and solutions:}

Considering the above points in the form of observation, we can see a need to create various changes in the system which can reduce the TAT. We discuss some of these options.

Automating redundant and manual processes: As the manual and time consuming activities can be reduced with automation. This will guarantee data validation and a reduced number of errors to improve the performance. The manual inward slip generation which is the bottleneck in the activity would be removed. As all the trucks need to collect the inward slip, at peak hours when more number of vehicles it will reduce the time by great extent. The QR code scanner is suggested which will reduce the time for generation of the inward slip generation by $90 \%$. Usually it takes $15 \mathrm{~min}$ for generation of inward slip, but with QR code bases system the entire data will be printed on a slip and this QR code can be used in the all divisions such as documentation, invoicing and loading. This will save lot of waiting time for drivers and it will decrease turn around time (Kucukaltan, Berk \& Herand, Deniz, 2014)

Process development: The entry process, loading and documentation process needs to be simplified so that any driver with any background should be able to understand the process. The entire document generation process can be made simpler to reduce, queuing time of drivers at respective departments. As loading and billing operation is at two warehouses, there is random and unnecessary movement of drivers in the plant location. This unorganised movement of drivers causes delay in the entire process. So SOP for drivers, loading supervisors and new process flow is required for the same to simplify the billing and loading operation.

Augment the resources: The resources working on the security gate, inward slip generation gate, loading office should be trained with the new technologies which are coming up so that the turn around time is reduced. The rotation of labours to learn different work in the same department will reduce the down time in the system and will also improve the overall skill set of resources. Thus, this facilitates the operational efficiency of different departments and creates backup resources for the absent workers (Azevedo, Susana \& Ferreira, João J. \& Leitão, João Carlos, 2008). The necessary shift of resources is critical in balancing the work of both the warehouse as there is more work on one particular due to current process flow.

So the new process flow is redesigned with all the parameters which would help in balancing the work, reduce the redundant work and movement of drivers inside the plant. This in turn would reduce the TAT for the trucks.

Current Process: 


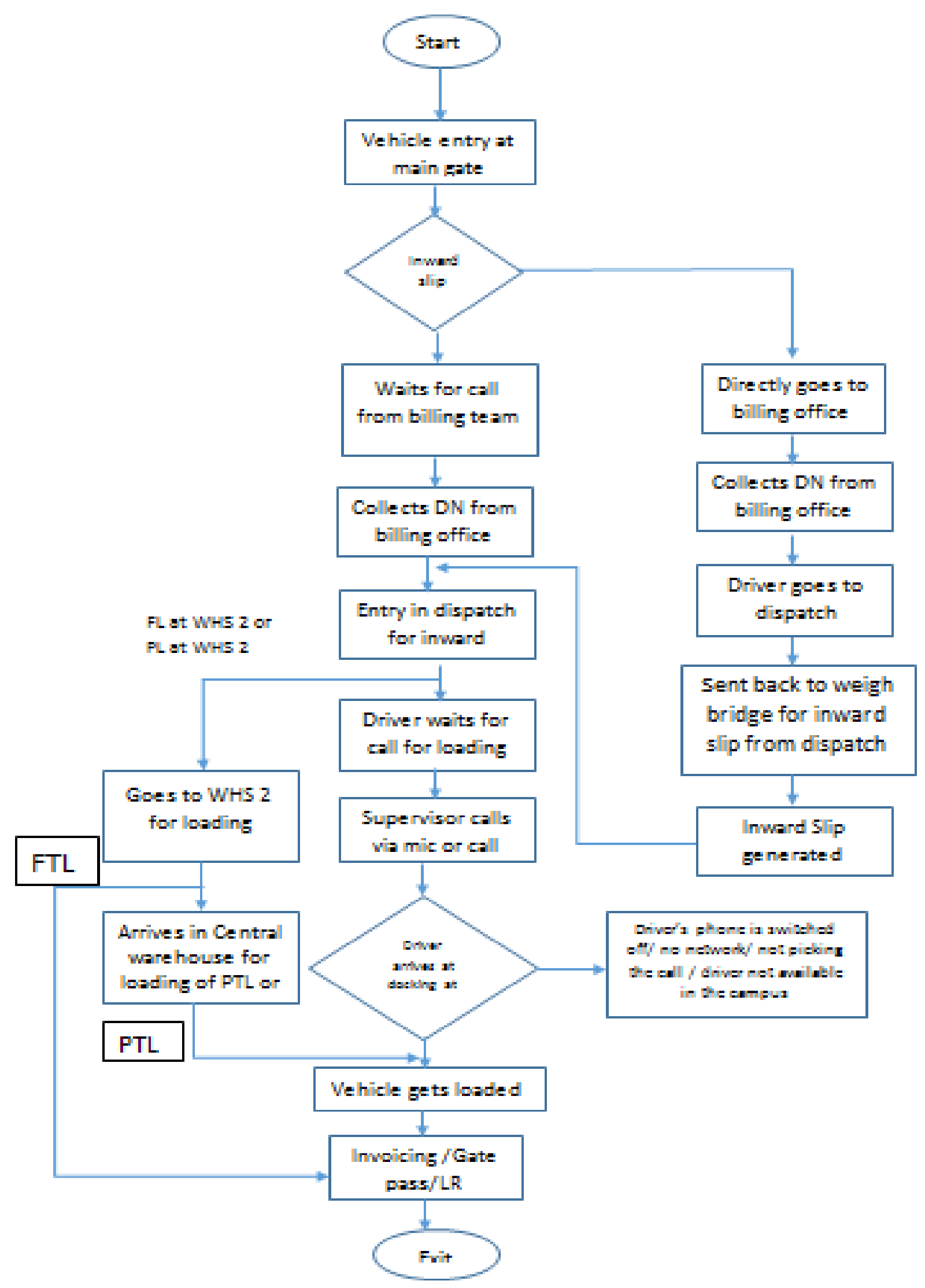


Proposed process flow:

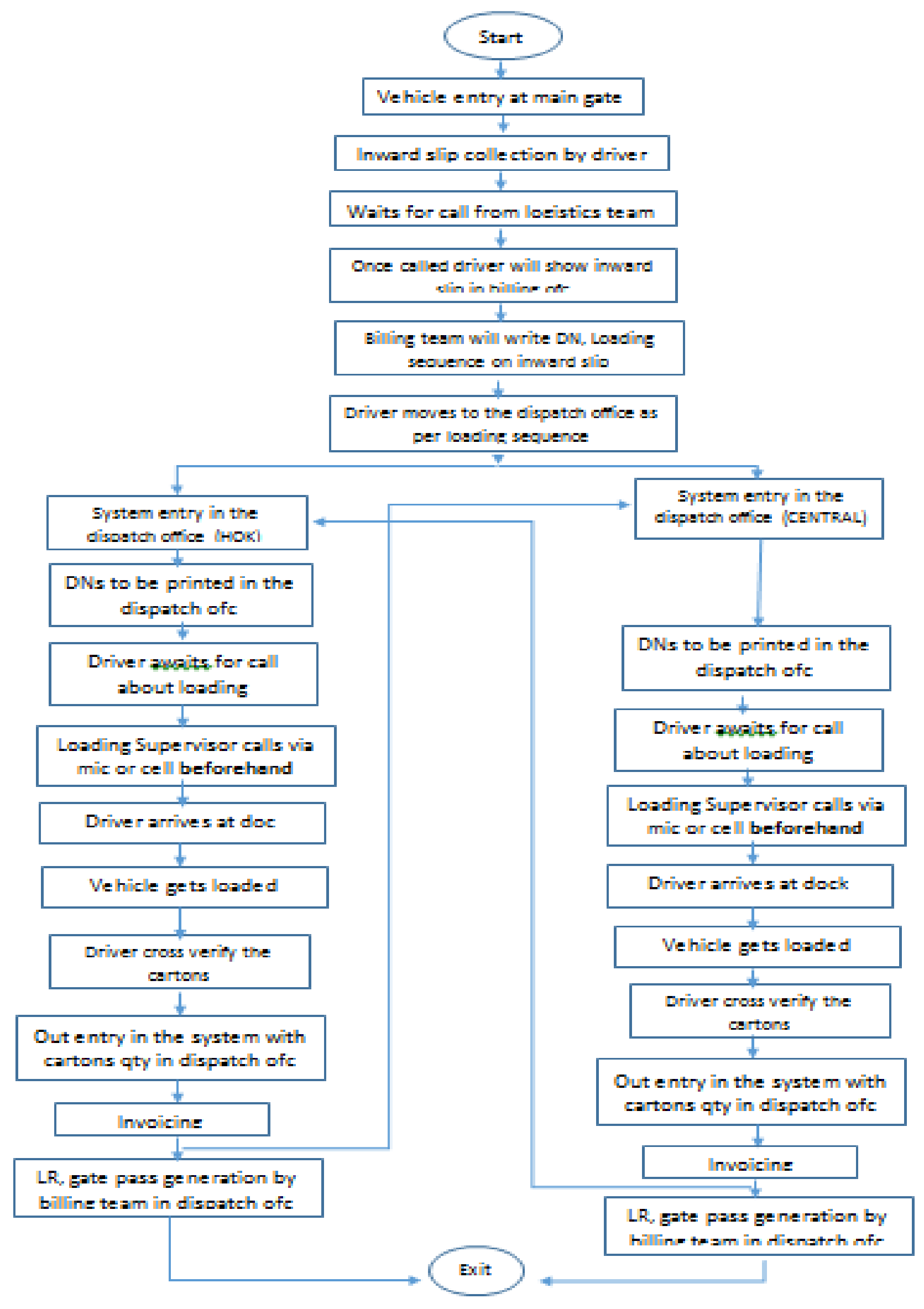




\section{CONCLUSION}

The paper has explained practical problems faced in managing the in-plant logistics in the context of a FMCG company in India. Consequently, the TAT of truck in-plant realized is very high as compared to the industry standards. A survey on drivers was conducted and various points were analysed to find the intricate issues in the plant. The major gaps are identified and departments in the plants, which contribute for significant increase in the TAT. Various solutions like automation redundant manual tasks including computerised generation of the inward slip, and balancing the work in both the warehouses, simplification of billing and LR generation processes to reduce the TAT. The various solutions with a redesigned process flow would cumulatively will address the problem (Habib, Muhammad \& Shah, Attaullah, 2013) The designing of SOP for loading supervisors and drivers with a structured process to reduce the barriers and inefficiencies in the system. The various technologies to integrate the entire inplant operation is available and the time reduction is huge. The major findings and results of the research is the time reduction after in-depth analysis of the system and constraints in it. This will definitely increase the productivity with long term approach to resolve the small issues and scale up the entire system.

\section{REFERENCES}

[1] Garrido Azevedo, S. and Carvalho, H. (2012), "Contribution of RFID technology to better management of fashion supply chains", International Journal of Retail \& Distribution Management, Vol. 40 No. 2, pp. 128-156.

[2] Vayvay, Özalp \& Dogan, Ozlem \& Özel, Semih. (2013). Forecasting Techniques in Fast Moving Consumer Goods Supply Chain: A Model Proposal. International Journal of Information Technology and Business Management. 16.

[3] Gilmour, Brad \& Gale, Fred. (2002). Transportation and Distribution: Will Bottlenecks Be Eliminated?. China's Food and Agriculture: Issues for the 21st Century.
[4] Kushal Parwani and R Jagadeesh, Reduction of Turnaround Time for Outbound Logistics (Finished Goods only) in a Food Processing Industry, 2012

[5] Kenneth Ruebrdanz, Distribution Center Management, 10 strategies to optimise your warehouse operations, 2011

[6] Ying, J Fei, John Tookey, and Johannes Roberti. 2015. 'SCM competencies in construction: issues and challenges in New Zealand', Journal of Engineering, Design and Technology, 13: 522-38.

[7] Rodrigues, Vasco \& Potter, Andrew \& Naim, Mohamed. (2010). The impact of logistics uncertainty on sustainable transport operations. International Journal of Physical Distribution \& Logistics Management. 40. 61-83. 10.1108/09600031011018046.

[8] Ülgen, Veronica \& Forslund, Helena. (2015). Logistics performance management in textiles supply chains: Best-practice and barriers. International Journal of Productivity and Performance Management. 64. 52-75. 10.1108/IJPPM-01-2013-0019.

[9] Khanzode, Vivek \& Shah, Bhavin. (2017). A comprehensive review of warehouse operational issues. International Journal of Logistics Systems and Management. 26. 346. 10.1504/IJLSM.2017.10002597.

[10] Stebbins, Robert. (2001). Exploratory research in the social sciences: what is exploration?. Exploratory Research in the Social Sciences. 2-18.

[11] Thompson, Cheryl. (2009). Descriptive Data Analysis. Air medical journal. 28. 56-9. 10.1016/j.amj.2008.12.001.

[12] Kucukaltan, Berk \& Herand, Deniz. (2014). QR Code Usage for Marketing Activities of Logistics Companies. Management. 4. 2733. 10.5923/s.mm.201401.04.

[13] Habib, Muhammad \& Shah, Attaullah. (2013). Business Process Reengineering: Literature Review of Approaches and Applications.

[14] Michael Hompel and Thorsten Schmidt, (2006), warehouse management Automation 
and Organisation of Warehouse and Order Picking Systems

[15] Azevedo, Susana \& Ferreira, João J. \& Leitão, João Carlos. (2008). The Role of Logistics Information and Communication Technologies in Promoting Competitive Advantages of the Firm. The IUP Journal of Managerial Economics. VI. 7-21. 